\title{
THE IMPACT OF LOWER LIMB AMPUTATION ON COMMUNITY REINTEGRATION OF A POPULATION IN JOHANNESBURG: A QUALITATIVE PERSPECTIVE
}

\begin{abstract}
The impact of non-traumatic lower limb amputation on participants during their reintegration to the community in South Africa is unknown.

Aim: To explore the experiences and perceptions of people with lower limb amputations from the Johannesburg metropolitan area on the impact that their amputations had on their lives and their return to their communities.

Methods: Semi-structured audio-taped in-depth interviews were used to collect data on 12 purposively selected participants. Ethical clearance was obtained. A General Inductive Approach was used to generate or discover themes within the data using a process of systematic coding.
\end{abstract}

Results: Emerging from the qualitative data were psychological, social and religious themes. Suicidal thoughts, dependence, poor acceptance, public perception about body image, phantom limb related falls and hopes of obtaining prostheses were reported. Some reported poor social involvement due to mobility problems and employment concerns, while families and friends were found to be supportive. Participants had faith in God.

Conclusion: Generally, most participants had come to terms with the amputation and were managing well while some expressed that they were struggling with reintegration to their communities of origin three months postoperatively with both functional and psychosocial challenges.

KEY WORDS: LOWER LIMB AMPUTATION, EXPERIENCES, OUTCOME, FEELINGS

\section{INTRODUCTION}

Diabetes is the leading cause of nontraumatic lower limb amputation (LLA) (Lazzini et al 2012; Nather et al, 2008). Ambulatory function has been reported to decline in the intermediate period following a LLA (Czerniecki et al, 2012, Godlwana et al, 2012). Godlwana et al,

\section{Correspondence Author:}

Lonwabo L Godlwana

Department of Physiotherapy

School of Therapeutic Sciences

Faculty of Health Sciences

University of the Witwatersrand

7 York Road

Parktown

Johannesburg, South Africa

Email: lonwabo.godlwana@wits.ac.za
(2012) found a significant decline in mobility at 3 months postoperatively ( $p=0.04)$ while Czerniecki et al, (2012) also found a decline in mobility at both 6 weeks and 4 months. Because of the mobility difficulties, people with amputations experience problems with activities of daily living including household chores, recreational activities and returning to work. The difficulties with social function affect their social relationships (Gallagher et al, 2011).

Psychological well-being is an important aspect of health and many people with LLA experience anxiety and depression (Mosaku et al, 2009). People with a LLA due to diabetes have poorer psychological adjustments to their situation (Couture et al, 2012; Coffey et al, 2009). LLA may result in psychological difficulties in coming to terms with the stump and body image (Couture et al, 2012). Evidence of body image disturbances surfaces as early as during hospitalization and while it varies across patients, it can persist (Couture et al, 2012). Even at a later stage some patients never fully acknowledge and accept their new situation (Couture et al, 2012; Zidarov et al, 2009). Body image disturbance results in high levels of anxiety, depression and emotional distress (Couture et al, 2012). Psychological problems may also result in physical deterioration not because the person cannot walk but because they choose not to do so and they may have negative attitudes towards treatment after the amputation (Desmond \& MacLachlan, 2006). 
In South Africa, there is limited information on the problems experienced by people following LLA. Godlwana et al, (2012) and Kamel, 2000 are the only studies that addressed these problems but not in a qualitative manner for the former. The latter studied patients' preoperative perceptions and thoughts about the amputation and the former quantitatively examined quality of life and various activity limitations from preoperative to three months postoperatively. The aim of this study was to explore the experiences and perceptions of people with LLA from the Johannesburg metropolitan area on the impact that their amputations had on their lives and their return back into their homes and communities.

\section{METHOD}

This qualitative study was nested within a larger quantitative study. Participants were drawn from the preoperative lists of people scheduled for first time major lower limb amputation at the three major hospitals in the Johannesburg metropolitan area. Participants were then followed up three months later and purposive sampling was used to select key informants (participants with rich information) for in-depth interviews $(\mathrm{n}=12)$.

Participants were included if they had first time unilateral (or bilateral amputation done at the same time) lower limb amputation. Those who had an amputation as a result of traumatic or congenital birth defects, and comorbidities that interfered with function preoperatively were not included. Institutional ethical approval was obtained. Participants gave informed consent prior to the in-depth interviews.
A demographic questionnaire, audio recorded semi-structured in-depth interviews and field notes were used to gather data. Interviews were conducted until data were saturated. Data were then transcribed and non-English data translated into English. A thematic approach was used to analyze the concepts by coding, categorising and developing themes that emerged in the qualitative data. Independent line by line coding by a qualitative researcher not involved in the study was done and these were consistent with those of the researchers. Quotes are used to give the participants' perspectives. A member check was conducted.

\section{RESULTS AND DISCUSSION}

Twelve in-depth interviews were conducted. The participants had a mean age of 52 years $(\mathrm{SD} \pm 7.5)$. Nine of the participants were male and six had a below knee amputation. .

Three main themes emerged from the analysis (table 1): psychological, social and religious. These are discussed below and illustrated by quotes (pseudonyms have been provided for participants).

\section{Psychological impact}

Psychologically the participants dealt with many hardships following their lower limb amputation. The new experience of having to face the world without a limb resulted in a state of shock and disbelief, as expressed by JOHN:

"I was always miserable. I used to think, why should the world be so unkind to me?"

The reality of not knowing what to expect and the necessary adjustments and adaptation following the ampu- tation was of concern. Uncertainties about life in the future were expressed, especially regarding the extent of physical limitations and the impact of the amputation on functional recovery and independence. This included return to work or the possibility of finding employment as illustrated by THOMAS' story: ...during his early stages while he was still in hospital Thomas said that the amputation initially resulted in misery and a state of doubt as to whether he would ever be the same again.

Participants feel dependent, hopeless (Mosaku et al, 2009, Schoppen et al, 2003) stressed and miserable. This difficulty in psychological adjustment following LLA is common (Couture et al, 2012; Coffey et al, 2009). They told of how they went into a state of shock following their amputation, leaving them dependent, hopeless and feeling depressed and anxious.

THOMAS: "I was not sure what sort of impact its gonna have in your life."

For some, these experience and encounters also made them feel that they had been wronged or they did not feel that they deserved to lose their limb. They expressed a sense of unfairness due to the event, eloquently stated by THOMAS:

"I have been cheated out of a lot of things. I feel that I miss out of a lot of things."

Participants expressed uncertainties about their futures and were concerned about the implications of the amputation on their jobs and position in the community (Kamel, 2000). They felt that they had to accept any job and that their life plans had changed (Amosun et al, 2005). Thomas expressed that he was

Table 1: Emerging themes

\begin{tabular}{|l|l|l|l|}
\hline Themes & Psychological & Socioeconomic & Religious \\
\hline Categories & $\begin{array}{l}\text { Shock, disbelief, uncertainty about life, coping, adjustment, } \\
\text { hopelessness, misery, depression, anxiety, feeling wronged by } \\
\text { the event, unfairness of the event, job seeking, falls and risk of } \\
\text { falling, phantom sensations, sympathy from the community, body } \\
\text { image disturbance, pain, sleep disturbance, suicidal thoughts, } \\
\text { embarrassment from bowel incontinence, lifestyle modification, } \\
\text { attitude (positive attitude) from the family. }\end{array}$ & $\begin{array}{l}\text { Work, family support, financial } \\
\text { implications, disability grant, } \\
\text { being a burden on the } \\
\text { family, status in the society, } \\
\text { social interaction, social } \\
\text { participation. }\end{array}$ & $\begin{array}{l}\text { Faith in God, God's will, } \\
\text { God will care for me, prayer. }\end{array}$ \\
\end{tabular}


concerned that he may find himself in a position where he is being discriminated against when he seeks jobs in the future as well as in matters pertaining to society.

THOMAS: "Will people discriminate against you because of your disability?"

Many had stability problems and this caused falls. Others had phantom limb sensations and this resulted in trying to take a stride on the stump forgetting they no longer had the full limb and falling. They ended up modifying activities like dressing to make them easier and saw this as reducing their frustration and the risk of falling. People with LLA have to relearn their usual activities (Bosmans et al, (2007). Thomas expressed how he had to be more alert when doing usual activities as opposed to his preoperative status and consciously be aware of his stability to avoid falling.

THOMAS: "Generally you do things without thinking and it's a natural thing that I turned and lost my balance."

In public places, people were sympathetic and felt pity for the participants at times.

MARK: "In the street people are sympathetic."

A LLA changes one's physical appearance and thus it was not surprising that participants reported that they were self-conscious about their image. This was especially true when they were in public places as they felt that the public perceived them differently. Attempts to preserve normal physical appearances were reported. They insisted on wearing long pants with the prostheses to make sure that when they went out, people who did not know would not notice. They were also conscious about how children tended to stare at them in public places. Even in their own families they felt that, although they were supportive, the family was more comfortable when they saw them wearing their prostheses as though they were embarrassed by the patient's physical appearance (Zidarov et al, 2009).

THOMAS: "all I am waiting for is a prosthesis because once I have that on and I have long pants on and I don't have crutches with me no body is gonna notice that I have got a disability."

The participants body image was also affected by the lack of consideration for the participants by society. People joked and made inconsiderate comments about the amputation. This was frustrating and they reacted with anger, rage and disappointment. A participant was advised by someone (elder in the community) not to internalize or listen to these comments. Body image disturbance is a major problem following LLA (Couture et al, 2012; Zidarov et al, 2009; Fisher \& Hanspal, 1998, Breakey, 1997).

SIPHO: "in the streets people say a lot of things, some of which hurt me."

"People tend to make jokes about your situation and they do not even know you. This seems to fascinate some of them and others empathize with you. Others understand that this is no playing matter."

"I have tried to stop these jokes in the beginning when I had just been back from the hospital. I used to really take them personal, I used to get furious or aggressive."

THOMAS: “... disbelief that something like this could ever happen to me. I found it very hard to come to terms with it."

Participants mostly did not seem to relate their pain experience to functional limitations, thus experiencing stability and balance challenges rather than pain inhibiting their function. Some however did experience a great deal of pain and discomfort. The pain was unbearable and so uncomfortable that it impacted on their sleep and resulted in sleep disturbances. It is, interesting to note that Bosmans et al, (2007) found that people with a LLA reported higher subjective well-being in spite of suffering severe phantom pain whereas those with hardly any pain rated their subjective well-being as low. Other forms of discomfort and pain experienced were those related to the vulnerability of the stump during the use of the prosthesis. The newly issued prosthesis may result in discomfort due to friction against the skin of the stump.
Such discomfort can result in people with amputation having reservations about using the device.

MARK "This Saturday I had to go out and wore the prosthesis again, I experienced a great deal of discomfort with it."

"The stump muscle was extremely sore and I realized that it was all the walk."

"I walked up six flights of stairs that Saturday so I know that I had over exerted myself."

Some had suicidal thoughts during their recovery time postoperatively. They did not want to live and they contemplated taking their own lives. Giving up and feeling that it was better to die can occur following lower limb amputation (Kamel, 2000).

JOHN: "I used to even think of suicide but my girlfriend said I mustn't take my own life."

Other emotions experienced included the embarrassment of feacal incontinence. This challenging psychosocio-physical problem puts a person in a compromised position. In a study by Misajon et al, (2006) mobility impaired participants reported distress in selfcare, however, their study involved mobility impaired patients in general and not specifically patients with LLA. While only Mary expressed this concern in the qualitative study, Godlwana et al, 2012 reported a significant $(p=0.04)$ preoperative to postoperative decline in bowel function as examined by the Barthel index in the quantitative wing $(\mathrm{n}=40)$ of this study.

MARY: "I developed bowel incontinence immediately after the amputation."

Others seemed to have found the best solution for their limb condition was to have an amputation. It seemed as if the operation was all they had been waiting for and now that they had had it, they were fairly happy and coping well. Mac Neill et al, (2008) found that some people with a lower limb amputation report functional independence.

BILL: "No pains, I don't feel anything else. It's like losing a leg is not a 
problem. I help myself with whatever. The amputation has had no impact on my life. It has made no difference. I am coping well, I have no stress, nothing."

This participant was very cheerful during the interview and did not seem concerned about any aspect of his life yet his stump was still being dressed.

BILL: "I do things like I did before, the difference is that it is time consuming."

Some were able to draw positive inspiration from the amputation. They tried to live a positive life, keeping a positive attitude. Some even modified their lifestyles by ceasing smoking and drinking, ate healthier and looked at life such that they could get the best out of it.

BILL: "You must learn to accept it." THOMAS: "I don't look at my disability as a setback, I look at it as a challenge. I try and maintain a positive attitude as much as I can."

Participants reported being close to people who were supportive, people who cared, people who gave him/her the inspiration needed to face the reality of losing a leg and provided a force to pull through. In this study, these were in the form of a spouse, a parent, siblings, and friends.

THOMAS: "I think it's because I'm surrounded by people that have all this positive attitude and that positiveness tends to rub off on you."

Other ways of coping, staying positive and avoiding destructive situations involved managing and handling stress well. Some even made every effort to control their blood glucose levels.

JOHN: "I think I am back to normal.

I don't want to stress and my sugar goes up."

Others expressed relief and satisfaction. The amputation did not bother them.

NATHAN: "I feel quite fine."

BILL: "I have no anxiety, I am back to $100 \%$.”

These varying ways of adjusting, coping and adapting to a lower limb amputation including acceptance have also been reported elsewhere (Desmond and MacLachlan, (2006). Desmond and MacLachlan, (2006) showed that some patient cope and adjust well following a lower limb amputation.

\section{Socio-economic impact}

The participants in this study faced socioeconomic challenges. Some were under the age of sixty and would have liked to work and support their families and were worried about being unemployed and the impact this had on their roles in the family. They did not like being dependent and were worried about the financial implications of rehabilitation as they were unemployed. In other instances same did not even have the money to go to a clinic to arrange and start processing their disability grants.

The participants, with children, did not like being a burden on them especially in cases where the children's wages were low. Financial concerns and high unemployment are common in people with amputations (Poljak-Guberina et al, 2005 and Kamel, 2000). Bosmans et al, (2007) showed that their participants were happy to have a job and this helped them achieve some status in their society and better social well-being. The need for a disability grant is often expressed so as to ensure an income (Amosun et al, 2005).

PETER: "Now I am bothered by the fact that I am not working. I just need to see the doctor and get my pension."

Some lost their income as they could no longer cope with their previous occupation (Burger and Marincek, 2007). There is uncertainty and confusion about the future and educated participants tend to worry more about losing their occupational position than their less educated counterparts who hope for a disability grant (Kamel, 2000).

The families and relatives were very supportive and these included the spouse, parents and friends. High levels of seeking social support and lower levels of avoidance as a coping strategy improve social adaptation (Desmond and MacLachlan, 2006). Participants often have positive support and improved relationships with their partners and relatives following a lower limb amputation (Bosmans et al, 2007; Couture et al, 2012). BILL:

"My whole family was supporting me."

THOMAS: As far as my friends are concerned they have done remarkable things."

The participants faced challenges and limitations including social interaction during their time of reintegration to their communities. At times they were unable to join fellow family members in social outings and events. The instances where they decided to join in an outing, they chose to remain in the car while friends and family enjoyed the particular event (Taylor et al, 2005). Kamel, (2000) reported participants' withdrawal from social interaction as they were pessimistic, worried, desperate, anxious, and sad.

Dependency hampered participants in carrying out their daily activities of shopping, working, pursuing hobbies, participation in sport and visiting family and friends thus hampering them in their usual activities and usual social affection. They reported that they were not happy that they had to give up activities they previously enjoyed with their partners (Taylor et al, 2005 Gallagher et al, 2011).

Some, despite all the challenges faced by people following lower limb amputation, remained independent in activities of daily living Mac Neill et al, (2008). Others demonstrated how they had since tried to return to various activities.

\section{Religious impact}

Participants tended to put their faith in God. They felt that God had decided that they had to have the amputation and therefore God would take care of them. They did not see the need to question anything and they said that God had all the answers. They felt that through prayer, they would overcome. This coping skill was expressed in a way that suggested that they did not have much to worry about as far as the amputation was concerned as God would lead the way. They relied on faith and their family and friends also 
prayed for them. Kamel, (2000) on the contrary reported that participants felt that having an amputation was unfair and that they were being punished by God. They asked why it had to be them that had to undergo an amputation.

BILL: "Although you don't know where it comes from, God knows why." THOMAS: "I managed to get used to the idea with the help and prayers of my friends and family."

These participants were of the view that if they did not believe in God, then $\mathrm{He}$ would not help them. He would not be there to guide and protect them. Prayers played a vital role in assisting them accept and cope with this devastating experience.

THOMAS: "I know a miracle can still happen, I can get my life back to normal."

\section{CONCLUSION}

Generally, most participants had come to terms with the amputation and were managing well while others expressed that they were still struggling with reintegration to their community of origin three months postoperatively with both functional and psychosocial challenges. Participants had faith in God and believed that He would lead and protect them. The participants had difficulties with issues of body image, pain, risk of falling and poor functional independence during their reintegration back into the community which affected their well-being. Others were satisfied with the outcome of the amputation and reported coping well during this period of their recuperation.

\section{Implications for practice}

This paper highlights that patients in their first three months post LLA are vulnerable during reintegration to their community of origin, with psychosocial, socioeconomic problems, issues of body image, pain, risk of falling and poor functional independence. Some are satisfied with the outcome of the amputation and reported coping well during this period of their recuperation.

Healthcare practitioners must keep these outcomes in mind and address them accordingly in an interdisciplinary team, especially considering that most of the physical/functional challenges are impacted directly by psychological challenges and it is therefore not appropriate to address the physical challenges in isolation.

\section{REFERENCES}

Amosun SL, Mutimura E, Frantz JM, 2005. Health promotion needs of physically disabled individuals with lower limb amputation in Rwanda, Disability and Rehabilitation, 27(14): 837-847

Bosmans J C, Suurmeijer T P.B.M, Hulsink M; van der Schans C P, Geertzen, J H.B, Dijkstra PU, 2007. Amputation, phantom pain and subjective well-being: a qualitative study, International Journal of Rehabilitation Research, 30(1):1-8

Burger H, Marincek C, 2007. Return to work after lower limb amputation, Disability and Rehabilitation, 29(17): 1323-1329

Coffey L, Gallagher P, Horgan O, Desmond D, MacLachlan M, 2009. Psychological adjustment to diabetes-related lower limb amputation- short report, Diabetic Medicine, 26: 1063-1067

Couture M, Desrosiers J, Caron C 2012.Coping with a lower limb amputation due to vascular disease in hospital, rehabilitation, and home setting, International Scholarly Research Network Rehabilitation, article ID 179878, 9pages, dio: $10.5402 / 2012 / 179878$

Czerniecki JM, Turner AP, Williams RM, Hakimi KN, Norvell DC 2012. Mobility changes in individuals with a dysvascular amputation from the presurgical period to 12 months postamputation, Archives of Physical Medicine and Rehabilitation, 93: 1766-1773

Desmond DM, MacLachlan M, 2006. Coping strategies as predictors of psychosocial adaptation in a sample of elderly veterans with acquired lower limb amputation, Social Science\& Medicine, 62: 208-216

Engstrom B, Van de Ven C, 1999. Therapy for amputees, $3^{\text {rd }}$ edition, Churchill Livingstone page $1-96$

Fisher K, Hanspal R, 1998. Body image and patients with amputations: does the prosthesis maintain the balance, International Journal of Rehabilitation Research, 21: 355-363

Gallagher P, O'Donovan M, Doyle A, Desmond, D 2011.Environmental barriers, activity limitations and participation restrictions experienced by people with major limb amputation, Prosthetic and Orthotics International, 35 (3): 278-284

Godlwana L., Stewart A, Musenge E.2012. Quality of life following a major lower limb amputation in Johannesburg, South Africa. South African journal of Physiotherapy; 68 (2); 17-22

Kamel EH, 2000 The thoughts and feelings of patients submitted to an amputation of a limb about the operation: Thesis (unpublished), Medical University of Southern Africa
Lazzarini PA, O'Rourke SR, Russell AW, Clark D, Kuys SS 2012. What are the key conditions associated with lower limb amputations in a major Australian teaching hospital? Journal Of Foot And Ankle Research, 5:12 BioMed Central Open access http://www.jfootankleres. com/content $/ 5 / 1 / 12$

Mac Neill HL, Devlin M, Pauley T, Yudin A, 2008. Long-term outcome and survival of patients with bilateral transtibial amputations after rehabilitation, American Journal of Physical Medicine and Rehabilitation, 87 (3):189-196

Misajon R, Manderson L, Pallant JF, Omar Z, Bennet E, Rahim RBA, 2006. Impact, distress and HRQoL among Malaysian men and women with a mobility impairment, Health and quality of life outcomes, BioMed Central. Open Access on the 22-06-2009.

Mosaku KS, Akinyoola AL, Fatoye FO, Adegbehingbe OO, 2009. Psychological reactions to amputation in a Nigerian sample of amputees, General Hospital Psychiatry, 31, (1): 20-24

Nather A, Bee CS, Huak CY, Chew JLL, Lin CB, Neo S, Sim EY 2008. Epidemiology of diabetic foot problems and predictive factors for limb loss, Journal Of Diabetes And Its Complications, 22: 77-82

Pell JP, Donnan PT, Fowkes FGR, Ruckey CV, 1993. Quality of life following lower limb amputation for peripheral arterial disease, European Journal of Vascular Surgery, 7:448-45

Poljak-Guberina R, Zivkovic O, Muljacic A, Guberina M, Bernt- Zivkovic T, 2005. The amputees and quality of life, Collegium Antropologicum, 29(2): 603-609

Resnick HE, Carter EA, Lindsay R, Henly SJ, Ness FK, Welty TK, Lee ET, Howard BV, 2004. Relations of all lower-extremity amputation to all-cause and cardiovascular disease mortality in American Indians, Diabetes Care, 27 (6):12861293

Schoppen T, Boonstra A, Groothoff JW, De Vries J, Goeken LN, Eisma WH, 2003. Physical, Mental, and Social Predictors of Functional Outcome in Unilateral Lower-Limb Amputees, Archives of Physical and Rehabilitation Medicine, 84: 803-11

Taylor SM, Kalbaugh CA, Blackhusrt DW, Hamontree SE, Cull DL, Messich HS, Robertson RT, Langan EM, York JW, Carsten CG, Snyder BA, Jackson MR, Youkey JR, 2005. Preoperative clinical factors predict postoperative functional outcomes after major lower limb amputation: An analysis of 553 consecutive patients, Journal of Vascular Surgery, 42(2):227-234

Zidarov D, Swaine B, Gauththier-Gagnon C, 2009. Quality of life of persons with lower limb amputation during rehabilitation and at 3-months follow up, Archives of Physical Medicine and Rehabilitation, 90(4): 634-645 


\section{Appendix for methodology followed in the manuscript}

\section{“The impact of Lower limb amputation on community reintegration of a population in Johannesburg: a qualitative perspective"}

\section{PARTICIPANTS}

This qualitative study was nested within a larger observational study which used quantitative methods. As part of the larger study $(n=73)$ this qualitative component received data from key informants selected for semistructured in-depth interviews $(n=12)$. The selection process sought to obtain information from participants who were knowledgeable about the particular experiences, encounters and the impact of the amputation on their lives as described by Greenberg and Rosenheck, (2008). In this manner, participants purposively sampled were those who provided rich information and useful insights into their experiences. In addition, a diverse sample was chosen to represent a range of characteristics in terms of the level of amputation, personality (those who were lively and outspoken and those who were silent in nature), minority ethnic groups (e.g. the coloured race) and socio-economic status as described by Green et al, (2006). Participants were chosen from those, who when recruited for the larger study and gave informed consent to be part of the qualitative study too. Participants were recruited and interviewed until no new information was emerging and it was deemed that a point of data saturation had been reached as described by Bhandari et al, (2003). All participants provided informed consent to be interviewed and consented for these interviews to be audio-recorded.

\section{DATA COLLECTION:}

\section{IN-DEPTH INTERVIEWS WITH KEY INFORMANTS.}

Semi-structured interviews with key informants were conducted by the first author to collect qualitative data on the specific domains of feelings, experiences, functional, and psycho-social impact of LLA on these participants. Interviews lasted approximately an hour and were audio-recorded. Interviews were conducted in a location chosen by the participants, for example their homes or the primary health care clinic. In these sessions, open ended questions and probe questions were used to gather data from participants. These questions are shown in Table 1. The questions were developed based on the objectives of the study and on the authors' experiences of working with people with amputation

Participants were given the opportunity to explain and narrate their experiences on each of the questions and nonverbal communication was observed and recorded for reporting by the interviewer, for example their mood, facial expression, gestures and attitude while reporting. All participants were told that there was no right or wrong input, participants were encouraged to say whatever they felt or had experienced.

The first author conducted all the interviewed in English or Zulu as preferred by the participants. Participants who preferred Sotho were interviwed by a trained research assistant.

\section{DATA ANALYSIS}

A General Inductive Approach (Thomas, 2006) was used to generate or discover themes within the data using a process of systematic coding. The audio recordings were transcribed word for word by by the interviewers who conducted the sessions. The Zulu and Sotho data were transcribed and then translated into English by a translator who was fluent in both languages. Following this, as described by Krueger and Casey, (2000) a second person (familiar with the study) verified the translations for their contextual sense. These transcripts were analyzed together with the field notes taken during and after the in-depth interviews.

The transcripts were read through multiple times independently by the two authors to establish common concepts. Line by line reading and analysis ensured a thorough and verifiable identification of concepts. The authors then compared and discussed their concepts for consistency and came to a consensus where there were discrepancies of opinions.

The concepts were then grouped in discrete categories. Following this, similar categories were grouped in broader categories and coded in order to reduce the data in such a way that comparisons could be made across all in-depth interviews. The broader categories were thus the themes that emerged from the data (Krueger and Casey, 2000). Relations and associations between the categories were then made so that the most important themes from the data could be outlined. The exact language of the in-depth interviews was analyzed within the meaningful segments of speech. Similarities found in various data sources were identified. Data were compared and contrasted from different sources in the study (Denzin and Lincoln, 2000; Krueger and Casey, 2000). The two coders were independent and then the categories were brought together to see the amount of overlap between the categories.

Member check: Tapes were played back to the participants for their comments and additions to the original interview. During these sessions, quotes from their interview and how they had been interpreted was available for the participants to comment to ensure that what they said during the interview was interpreted in the way they would like it understood.

\section{Table 1:}

Probe questions may be used to facilitate the conversation.

1. Please share your experiences and feelings about the impact of your amputation in your life.

2. What are your experiences about your general function since you returned home after the operation?

3. Are there any other issues you would like to add? 


\section{CREDIBILITY AND TRUTHWORTHINESS}

Transcripts were checked by the second author to ensure that they did not contain obvious mistakes - what do you mean by mistakes? What you want participants to do is to verify that the transcripts has actually captured what they were getting at made during transcription. A robust systematic process was used in the analysis. All efforts were made to ensure that there was no drift in the definition of codes or a shift in the meaning of codes during processing. Two independent people were used to code the transcripts and their findings compared for consistency. Codes were cross-checked by comparing results that were independently derived by the two coders (Creswell, 2009).

After the initial coding was complete, a third coder was given the evaluation objectives, the categories developed, and the descriptions of each category with the raw data attached. This was done to check the clarity of the categories. As recommended by Thomas (2006), following this process the third coder allocated the same text segments with minor suggestions for alterations to improve clarity. A high rate of overlap was achieved indicating no further discussion and analysis to develop coding for this study (Thomas, 2006).

Triangulation was used to enhance the quality of the research, particularly credibility, trustworthiness and the authenticity of the data (Creswell, 2009; Krefting, 1991). Data were collected bytwo means were compared (e.g. in-depth interviews, participant observations). Triangulation of data sources was used to maximize the range of data that might contribute to complete understanding of the concept. The time and space of the participant interviews were varied, e.g. participants were interviewed on different days (i.e. weekdays and weekends), different settings (i.e. home and hospital settings), different groupings of people (by race and socioeconomic status) (Krefting, 1991). During interviewing, credibility was enhanced by reframing of questions, repetition of questions and probing questions on the matters raised by the participants (Krefting, 1991). During data analysis, themes were established based on converging several sources of dataor perspectives from participants (Creswell, 2009).

Trustworthiness- Data saturation: sufficient in-depth interviews were conducted until there was no longer new data coming from the participants. Specificity and emotions, expressions, feelings, perceptions, gestures and nonverbal cues are described in a narrative style (Krueger and Casey, 2000). In addition, the results are discussed and critically analyzed with reference to the modern literature in lower limb amputation research.

\section{REFLEXIVITY}

The authors were physiotherapists who had experience in rehabilitation following amputation as such had their own perceptions of what it must be like living with the impact of amputation. To ensure these perceptions did not influence unduly the questioning and the analysis of data, the authors discussed their perceptions to take ownership of them or "box" them. Furthermore the first author is multilingual and established a rapport with many of the participants and could truly understand the context of their views and the participants were able to open up more freely with him. Efforts were made to ensure that the researcher's gender, culture, history and socioeconomic origin did not affect the interpretation of the data (Creswell, 2009). Information found during the study but contrary to the general perspectives of the themes was discussed. This assisted in adding to the credibility of the data presented in this study and allows the study to be more realistic and valid (Creswell, 2009).

\section{REFERENCES}

Bhandari M, Devereaux PJ, Swiontkowski MF, Schemitsch EH, Shankardass K, Sprague S, Guyatt $\mathrm{GH}, 2003$. A randomized trial of opinion leader endorsement in a survey of orthopaedic surgeons: effect on primary response rate, International Journal of Epidemiology, 32: 634-636

Creswell JW, 2009. Research design, qualitative, quantitative, and mixed methods approaches, Sage publications: $173-202$

Denzin NK and Lincoln YS, 2000. Handbook of qualitative research $2^{\text {nd }}$ ed, Sage publications, inc. page $632-851$

Green CJ, Fortin P, Maclure M, Macgregor A, Robinson S, 2006. Information system support as a critical success factor for chronic disease management: Necessary but not sufficient, International Journal of Medical Informatics, 75: 818-828

Greenberg GA, Rosenheck RA, 2008. An evaluation of an initiative to improve coordination and service delivery of homeless service networks, The Journal of Behavioral Health and Research, 22-06-2009

Krefting L, 1991. Rigor in qualitative research: The assessment of trustworthiness, The American Journal of Occupational Therapy, 45(3): 214-222

Krueger RA, Casey MA, 2000. Focus groups: a practical guide for applied research $3^{\text {rd }} \mathrm{Ed}$, Sage publications, 5-192

Thomas DR, 2006. A general inductive approach for analyzing qualitative evaluation data, American Journal of Evaluation, 27: 237-246 